\title{
Usability principles for the design of virtual tours
}

\author{
Y. Pérez ${ }^{\text {a }}, \underline{\text { S. Berres }}{ }^{\text {b }}$, E. Rodríguez ${ }^{\text {a }}$, S. Rodríguez ${ }^{\text {a }}$, G. Antúnez a

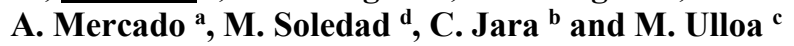 \\ ${ }^{a}$ University of Granma, Cuba, ${ }^{b}$ Catholic University of Temuco, Chile, ${ }^{c}$ Technical University of Cotopaxi, \\ Ecuador, ${ }^{d}$ National University of the Northeast of the Province of Buenos Aires, Argentina, \\ Email:sberres@uct.cl
}

\begin{abstract}
Museums are places of education, which are open and accessible to the general public. The diversity of the visitors puts museums in the role of a reference educational environment, where different methods and strategies can be developed and tested. The diversity of cultural and educational visitor backgrounds raises the challenge to adapt the museum tour guidance to specific interests and needs. New technologies are supporting an individually guided visit by mobile devices like tablets, smartphones or 3D glasses. However, along which lines could such an individually guided visit be designed?

This contribution provides a detailed definition of usability principles for virtual realities that are for instance designed as virtual tours or interactive educational environments. In two case studies, the developed design principles are applied to museums as specific reference environments, thus validating the applicability of the defined principles.

One main characteristic of the usability of a product is to be user-centered, giving an opportune response to user needs and requirements. The design of an interactive virtual tour should meet the requirements of a potential user, addressing aspects of interface, system functionality and interactivity, among others. This contribution elaborates usability principles for virtual tours, and validates them in two test scenarios.
\end{abstract}

Virtual tours in general are generated by software and presented on a screen or another display. According to guidelines applicable to general software products, they should be designed with the aim of allowing users to visit different sites and browse through them easily, allowing the users to find the information they need efficiently, when they need it and where they need it.

In this contribution, we understand by a virtual tour the predominantly audio-visual representation of a real site, its different aspects and the connections between them. As a feature, a virtual tour should allow individual interactions focusing on specific topics, in which a user is most interested. We assume that the virtual tour has the option to be coupled to a specific site in the sense that the virtual tour can be realized within this real site, thus coupling virtual and real experiences.

The perspective for further works is to apply the design principles in other contexts like guided tours of cities or through an archeological site. In a broader approach, the same principals also apply to any virtual reality environment, independent whether there is the option to connect the tour to a real location or not. The same design principles are also suited to be used to develop or improve interactive educational environments like virtual classrooms.

Keywords: Usability, usability principles, virtual reality, virtual tours, virtual educational environments 


\section{INTRODUCTION}

The topic of usability emerges in the field of Human-Computer Interaction, evaluating the phenomenon of interaction between users and software systems. The concept is not new, it was out there long before the emergence of tablets and even home computers. The concept originally was not as much centered in fun but rather in work. According to Shackel (1981), the usability of a system or equipment can be described as the availability of the system to be used by humans easily and effectively. Thereby, the ability of the users to comply with specific working tasks might be restricted to a specific group of user, which is provided by the necessary training and specific help. The main factors of usability are the ease of learning to deal with the tool, the efficiency of use it, and the satisfaction which people receive when they are able to fulfill their tasks when using the product they are working with. All these factors point to the need of a user-centered design (Diaz et al, 2005; Sauro and Kindlund, 2005; ISO Standard 9241-11, 1998).

General usability techniques are not applicable to the interface to virtual reality systems, because they do not consider specific elements like interactivity and feeling of immersion, which are characteristic to these systems. A frequently applied technique to assess elements of usability of virtual environments is to ask for user feedback. There, the assessment focuses mainly on establishing and evaluating questionnaires. Such an approach typically asks for quantitative response, judging several criteria on a grading scale, thus delivering a huge amount of quantitative data. A qualitative response is more difficult to obtain, since specific qualitative feedback are not systematic, strongly oriented to the specific questions, and if open questions are formulated then the most responsive feedback tends to be negative targeting at the detection of deficiencies. A complementary approach, which positively identifies properties to fulfill, is established by principles of usability.

A design of virtual reality that is aligned by usability principles promises to be beneficiary for both developers and consumers. Many researcher who have focused their activities in this and related field, see for instance Nielsen (1993), Norman (2002) or Van Velsen (2008).

The increasing development of virtual tours, combined with the emerging interest in the resulting applications, requires the proposal of specific usability principles for interactive virtual tours. This contribution proposes the definition of a set of usability principles, which form the basis for the design and evaluation of the usability of such environments.

In the University of Granma, which is located in the oriental region of Cuba, during the last 5 years several software applications for the cultural area have been produced. The production of virtual tours impacted significantly within the society by its use of exciting new technology. However, a proper and optimal implementation was hampered by the lack of important design guidelines for usability. A fundamental goal of this contribution is the definition of usability principles for virtual reality systems, which serve as design guidelines for the development of further products.

\section{METHODOLOGY}

The topic of virtual tours is a subfield of that of virtual reality. However, providing an accurate definition of the concept of 'virtual reality' is not a simple task. There are probably as many definitions as authors have worked in this area. In his entry to Encyclopedia Britannica, H. E. Lowood, a recognized scholar on the history of science and technology, defines virtual reality as 'the use of computer modeling and simulation that enables a person to interact with an artificial three-dimensional (3-D) visual or other sensory environment'. In order to increase the confusion, the same term 'virtual reality' is also used to refer to the branch of computer science involved in the development of corresponding systems; this aggregates all sorts of related concepts and procedures to the concept itself, thus blowing any focus if there ever was one.

Concerning a virtual tour, the particular site referred to by the tour is supposed to exist independently of its virtual representation. If the user of a virtual tour is immersed in the referred site, then the overall available sensations do not rely completely on the capability of the virtual representation. The task of the virtual tour is to give complementary orientations.

This contribution is an exploratory study on usability principles, focusing on their definition and tentative validation. The principles, which are addressed in the catalogue presented in Table 1 are inspired by the suggestions of several researchers working on the topic of usability around virtual reality, assessment techniques and design principles established in other areas. The reviewed studies include those of CervantesMedina (2003), Guzman-Garcia (2005), Villegas (2009) and Rodriguez-Juarez (2000). 
Pérez et al., Usability principles for the design of virtual tours

Table 1. Categories and classified principles of usability

\begin{tabular}{|c|c|}
\hline $\mathbf{y}$ & iples \\
\hline $\begin{array}{l}\text { Interaction } \\
\text { and Functionality. }\end{array}$ & $\begin{array}{l}\text { 1. The user is vividly immersed into the digital environment. } \\
\text { 2. Visualized objects have high resolution and clarity. } \\
\text { 3. The user is transported emotionally to another place. } \\
\text { 4. There is coherence between the user action and the system response. } \\
\text { 5. The system response is quick. } \\
\text { 6. The system provides audio-visual feedback. } \\
\text { 7. The user is represented by an animated character, which helps him to visualize his } \\
\text { actions. Other interacting characters visually express their states. } \\
\text { 8. The virtual environment changes its presentation dynamically. } \\
\text { 9. The links that launch applications are clearly identified. } \\
\text { 10. Rotation degree of at least } 45^{\circ} \text {, allowing clearly notable movements. } \\
\text { 11. The system does not shut down due to heavy objects. } \\
\text { 12. From the first interaction the user easily identifies the objective of the system. }\end{array}$ \\
\hline Pages. & $\begin{array}{l}\text { Main page: } \\
\text { 1. The main page contains good examples of the virtually represented contents. } \\
\text { 2. Easy orientation on the main page. } \\
\text { 3. All major options are displayed on the main page. } \\
\text { 4. The main page responds to the user where he is and what the system does. } \\
\text { 5. The main page counts with contact information. } \\
\text { All pages: } \\
\text { 6. All pages provide a short summary of their respective content. } \\
\text { 7. The initial menu has an understandable meaning, is available on every page, and has } \\
\text { a letter size larger than the letter size of the remaining text. } \\
\text { 8. The tag names in the menu are precise and short. } \\
\text { 9. There is a } 3 \mathrm{D} \text { site map, which indicates where the user is located and where he can } g \\
\text { move. The user can find all links to the different sections. } \\
\text { 10. The name and logo of the product is ubiquitous. }\end{array}$ \\
\hline $\begin{array}{l}\text { Navigation } \\
\text { system. }\end{array}$ & $\begin{array}{l}\text { 1. There is a clearly structured navigation system. } \\
\text { 2. The users are free to examine in detail what really interests them. } \\
\text { 3. The users have an adequate control over their actions. } \\
\text { 4. The graphical interface provides a navigation trail. } \\
\text { 5. All parts of the system follow the same interface design pattern. } \\
\text { 6. Visited links change the color. } \\
\text { 7. The menu changes color to indicate the current state. }\end{array}$ \\
\hline
\end{tabular}


Pérez et al., Usability principles for the design of virtual tours

\begin{tabular}{|l|l|}
\hline Panoramic view. & $\begin{array}{l}\text { 1. The images are generated depending on the current user position. } \\
\text { 2. There is a } 2 \text { or } 3 \text { dimensional image representation, depending on product purposes. } \\
\text { 3. The displayed objects are sufficiently realistic. } \\
\text { 4. The visualized contents are adequate and appropriate to different user groups. } \\
\text { 6. The view adapts to user actions, changing the view during user movement. } \\
\text { 7. The visualization mode corresponds to the user task or activity. }\end{array}$ \\
\hline Sound. & $\begin{array}{l}\text { 1. There is synchronization between sound and system action. } \\
\text { 2. The audio supports the orientation within the overall system. } \\
\text { 3. The audio explanations are easy to understand. } \\
\text { 4. Sounds or music are only used with the user's prior authorization. }\end{array}$ \\
\hline $\begin{array}{l}\text { Guidance } \\
\text { and Support. }\end{array}$ & $\begin{array}{l}\text { 2. The system guides the user on how to use the product. } \\
\text { 3. A search box is available. The search is structured by key words. }\end{array}$ \\
4. The search system includes examples and tips for an efficient use.
\end{tabular}

Six broad categories are defined, namely (1) Interaction or functionality, (2) Pages, (3) Navigation System, (4) Panoramic View, (5) Sound, and (6) Guidance and Support. The usability principles are defined and collected according to these categories, see Table 1. As general setup, it is assumed that there is a main page (principal page), which serves as center of organization.

\section{RESULTS OF CASE STUDIES: USABILITY CRITERIA APPLIED TO VIRTUAL TOURS}

In this Section, the applicability of the previously defined and classified user principles is validated, by applying them to two test situations. These two test cases consist of virtual tours through important museums in the Granma province, Cuba. The tours have been developed in collaboration projects of the University of Granma. In the design of these virtual tours, usability principles have not been applied systematically. Therefore, the examples are providing the lack of some principles, which demonstrates the need for usability principles for a proper product design.

\subsection{Usability test applied to virtual tour through the 'Celia Sánchez Manduley' museum}

As first test case, the virtual tour of the 'Celia Sánchez Manduley' museum is evaluated according to the determined usability principles.

I. Interaction and Functionality: A positive aspect of the virtual tour consists of the overall high visual resolution of the virtual tour, which provides a perceptible visual feedback and thus a dynamic user interaction. The links to run applications or to open new windows are identified by an icon or a corresponding text field. The rotation degree of over $45^{\circ}$ makes user movements clearly perceptible. However, the user interaction with the product does not generate a strong feeling of immersion, since the environment is received to be quite flat. Moreover, there is no consistency between the user actions and the system response. The system has no audio feedback. The virtual environment is not dynamic, generating the user the feeling of moving through a dead and empty world.

II. Pages: The main page contains good examples of the content of the rest of the system. It contains a text field for searching. There are no broken links on the main page. The page titles indicate briefly the page contents. The initial menu is comprehensible and available from all pages of the system. There is a 3D site map indicating the location of the user and possible next targets. However, there is not a well page structure that marks the beginning of the most important sections of the system. Also, there is no logo available. 
III. Navigation system: The navigation system has the flexibility to examine in detail topics of specific user interest, but there is no appropriate feedback on where the user is located. The link to the site map is not always available. The sitemap does not provide a concise overview. The navigation labels at the links are sometimes ambiguous. There is no 'Back' button. Finally, the visited links do not change the color.

IV. Panoramic view: There are two-dimensional visualizations. The changes of perspective are synchronized with the user movements. The displayed objects are very realistic, providing a good viewing angle. Moreover, the images are saved in galleries, where the specific image names allow the user to identify and find them in the system. However, the images are not generated according to the current user position, the display system does not adapt to user tasks.

V. Sound: This principle cannot be evaluated since there is no audio support in this virtual tour.

VI. Guidance and Support: The messages to the user are brief and unambiguous. Instructions indicate clearly to the users what to do. Error messages are redacted in a sensible tone. However, it is not easy to get help in a timely manner. The site does not provide a custom ' 404 page' that includes tips on how to find a lost page or a link to the initial page. No user confirmation is required before potentially dangerous actions as deleting something. The user is not warned about large pages that are going to load slowly (e.g. 'Please wait...'). The site does not provide additional feedback (e.g. 'Did You Know?') that helps to get acquainted with the site. The support is not clear, direct and expressed in a simple language, which is free of wordiness.

\subsection{Virtual tour through the 'Ñico Lopez Museum'}

As second test case, the virtual tour through the 'Nico Lopez Museum' is evaluated according to the established criteria.

I. Interaction and Functionality: As in the other test case, a positive aspect is the high visual resolution, and the perceptible visual feedback. The links to applications and new windows are indicated by icons or hypertexts. The possible rotation of more than $45^{\circ}$ allows a realistic representation of user movements. However, the system response is rather slow. Users interacting with the product do not feel to be immersed. There is no consistency between the user action and the system response. The system has no auditory feedback. The virtual environment is not dynamic, generating the user the feeling of being present in boring place.

II. Pages: The main page contains nice examples of the content provided by the system. The input to the system is easy to use. The principal page contains a text field for searching. The labels of the menu items are precise and not exceeding two words. The titles of the pages summarize the content of the corresponding page concisely. There is a 3D site map indicating the user location and reachable targets relative to the present position. However, in the principal page not all major system options are displayed. Also, there is no logo integrated. The initial menu is not uniformly available on all pages of the system. There is no mayor structuring of the content and the principal page does provide a direct access to the various features of the system.

III. Navigation system: The users have a high amount of flexibility to examine in detail what really interests them, having control over their actions. There is a clear orientation on the navigation system of the product. However, some terms used for the navigations are ambiguous. There is no 'back' button available. The overall content of the system is not suitable, the system appears to be heavy and overcharged with objects.

IV. Panoramic view: User movement and change of perspective are synchronized, as the image changes as the user moves in the virtual environment. The displayed objects look very realistic. There are appropriate viewing angles. The images are stored in the galleries and are accessible by the search for their indexed names. However, the images are not generated depending on the current user position. The presented objects do not have an appropriate measure that is related to the size of other objects in the environment, thus harming the similarity to a real world experience.

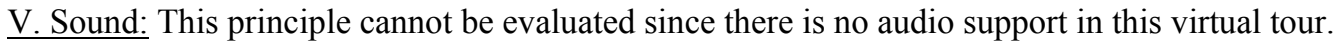

VI. Guidance and Support: In this test case no guidance and support system is implemented. 


\section{CONCLUSIONS}

Usability is a crucial quality attribute for any technology product, particularly including products in the area of virtual reality as virtual tours. In this contribution, a set of usability principles taking into account the specific characteristics of virtual reality systems are proposed in order to facilitate the design, development and evaluation of these environments. The defined usability principles have been applied to two virtual tours through museums.

\section{REFERENCES}

Díaz, M.P., Montero, S., and Aedo, I. (2005). Ingeniería de la Web y Patrones de Diseño, Pearson Education.

Lowood, H.E., Virtual reality. In: Encyclopedia Britannica, http://www.britannica.com/technology/virtualreality

Guzmán-García, M.E (2005). Uso de tecnologías de hardware gráfico en el apoyo al realismo en entornos virtuales arquitectónicos. Tesis no publicada. Maestría en Telemática, Facultad de Telemática, Universidad de Colima, México.

ISEA S. Coop. (2008), Internet 3D, Análisis prospectivo de las potenciales aplicaciones asociadas a los Mundos Virtuales.

Nielsen, J. (1993). Usability Engineering. Morgan Kaufmann.

Norman, D.A. (2002). The Design of Everyday Things.

Standardization, I.O.f., ISO 9241-1 (1998). Part 11 Guidance on usability.

Shackel, B. (1981). The concept of usability. Proc. IBM Software and Information Usability Symp. Poughkeepsie, NY, 15-18 September. for office work with visual display terminals (VDTs) -Part 11: 'Guidance on usability'. International Standards Organization.

Van Velsen L., Van Der Geest T., Klaassen R., and Steehouder M. (2008). User-centered evaluation of adaptive and adaptable systems: A literature review. Knowledge Engineering Review, 23 (3) , 261-281. 